\title{
Erratum to: Nanocellulose conjugated with retinoic acid: its capability to adsorb aflatoxin B1
}

\author{
Ali Jebali • Seyed Ali Yasini Ardakani • \\ Najme Sedighi - Seyedhossein Hekmatimoghaddam
}

Published online: 2 April 2015

(C) Springer Science+Business Media Dordrecht 2015

Erratum to: Cellulose (2015) 22:363-372

DOI 10.1007/s10570-014-0475-0

The correct affiliation of Dr. Seyed Ali Yasini Ardakani is provided here.

In the original publication of the article, the affiliation of the corresponding author has been published incorrectly.

The online version of the original article can be found under doi:10.1007/s10570-014-0475-0.

A. Jebali

Department of Medical Genetic, Shahid Sadoughi

University of Medical Sciences, Yazd, Iran

A. Jebali · S. A. Yasini Ardakani $(\bowtie) \cdot$ N. Sedighi Department of Food Science and Technology, Yazd Branch, Islamic Azad University, Yazd, Iran e-mail: a.yasini@gmail.com

S. Hekmatimoghaddam

Department of Laboratory Sciences, School of Paramedicine, Shahid Sadoughi University of Medical

Sciences, Yazd, Iran 